HUMANAS E SOCIAIS

V.9 • N.2 • 2021 • Fluxo Contínuo

ISSN Digital: 2316-3801

ISSN Impresso: 2316-3348

DOI: 10.17564/2316-3801.2021v9n2p215-228
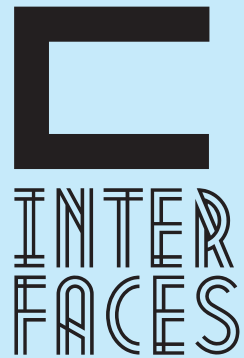

CIENTÍFICAS

\title{
A ESCRITA SIMPLES COMO ESTRATÉGIA DE ACESSIBILIDADE PARA A DIVULGAC̄̃̃O CIENTÍFICA
}

CLEAR WRITING AS A STRATEGY FOR ACCESSIBILITY TO SCIENTIFIC DISSEMINATION

LA ESCRITURA CLARA COMO ESTRATEGIA DE ACCESIBILIDAD PARA DIVULGACIÓN CIENTÍFICA

\section{RESUMO}

Os resultados de pesquisa científica, publicados em teses, dissertações e artigos, podem ser complexos e de difícil entendimento e acesso para a população em geral. Neste estudo exploratório foram analisados e reescritos cinco resumos científicos, a partir da aplicação de técnica de Escrita Simples (ES), com vistas à acessibilidade do conteúdo para Divulgação Científica (DC) a todos os públicos, incluindo pessoas com deficiência intelectual e/ou transtornos invasivos do desenvolvimento. As adaptações feitas nos resumos, sob a ótica da ES, permitiram elaborar 12 diretrizes iniciais, como estratégia para tornar mais equânime o acesso à DC.

\section{PALAVRAS-CHAVE}

Divulgação Científica. Escrita Simples. Acessibilidade.

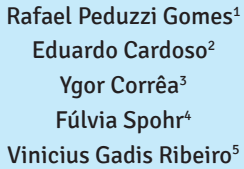




\section{ABSTRACT}

The results of scientific research, published in theses, dissertations and articles, can be complex and difficult to understand and to access for the general public. In this exploratory study five scientific abstracts were analyzed and rewritten through the application of Clear Writing (CW) technique, with a view to the accessibility of content for Scientific Dissemination (SD) to all audiences, including people with intellectual disabilities and/or invasive developmental disorders. The adaptations made to the abstracts, from the perspective of $\mathrm{CW}$, allowed us the elaboration of 12 initial guidelines, as a strategy to make the access to SD more equitable.

\section{KEYWORDS}

Scientific Dissemination. Clear Writing. Accessibility.

\section{RESUMEN}

Resultados de investigación científica, publicados en tesis o artículos, pueden ser complejos y difíciles de entender y acceder por la población en general. En este estudio exploratorio, fueron analizados y reescritos cinco resúmenes científicos a partir de la aplicación de técnica de Escritura Clara (EC), objetivando la accesibilidad del contenido para Divulgación Científica (DC) a todos los públicos, incluidas personas con discapacidad intelectual y/o trastornos invasivos de desarrollo. Las adaptaciones hechas en los resúmenes, desde la perspectiva de la EC, permitieron la elaboración de 12 directrices iniciales, como estrategia de hacer que el acceso a la DC sea más equitativo.

\section{PALABRAS CLAVE}

Divulgación Científica. Escritura Clara. Accesibilidad 


\section{INTRODUÇ̧̃̃o}

O processo de elaboração e de execução da pesquisa científica é complexo e pode ser demorado, tendo um impacto e legitimidade que acabam por não serem reconhecidos e compreendidos pela população no momento da comunicação dos resultados obtidos. Neste processo, pesquisadores definem o escopo, a temática e os objetivos da pesquisa, coletando e analisando os dados para o aprofundamento do estudo a fim de produzir conhecimento em caráter científico, o qual será compartilhado inicialmente no âmbito da comunidade científica.

O modelo de produção científica utilizado para a comunicação dos resultados entre a comunidade acadêmica dá-se, sobretudo, na forma de publicação de artigos em periódicos e eventos científicos. Um artigo científico configura-se na forma de comunicação ou disseminação científica, destinada, aos pares, compostos pelos demais membros da comunidade científica, que se configuram como leitores especializados.

Uma componente importante no processo de produção científica é a etapa de Divulgação Científica (DC), que tem como propósito básico a comunicação da informação científica e tecnológica ao público em geral (ALBAGLI, 1996). Por conta da DC, a ciência pode ampliar sua influência cultural, influenciando as diferentes práticas sociais e seus determinantes e, assim, guiar os processos decisórios de políticas, informando adequadamente gestores para a tomada de decisão nas mais diversas esferas públicas e privadas.

Dessa forma, considera-se que a DC desempenha um papel fundamental frente ao desenvolvimento social e tecnológico. Contudo, a comunicação de resultados científicos pode se tornar de difícil acesso a alguns públicos, como aos sujeitos com deficiência intelectual e/ou transtornos invasivos do desenvolvimento (MERCADANTE; GAAG; SCHWARTZMAN, 2006); Transtorno do Espectro Autista (TEA), pessoas surdas, cuja primeira língua é a Língua Brasileira de Sinais (Libras), pessoas com baixo letramento e/ou estrangeiros com dificuldades de compreensão do português (SOUSA, 2011; 2017).

Esta dificuldade estende-se ao público em geral, em virtude da DC ser composta por linguagem especializada e de escrita complexa e hermética. Considera-se a acessibilidade como possibilidade e condição de acesso para utilização de informação e comunicação (ABNT, 2016), ao se compreender que pode ser um recurso para tornar a comunicação científica acessível a vários públicos.

Este é um estudo de caráter descritivo (SAMPIERI; COLLADO; LUCIO, 2013), cuja metodologia foi composta por pesquisa bibliográfica e por uma Prova de Conceito (PC), como modelo prático para a verificação da adaptação de resumos científicos para Escrita Simples. O objetivo é verificar a viabilidade da adaptação de resumos científicos como iniciativa de acessibilidade da DC. Para tanto, foi selecionada uma amostra de cinco resumos científicos como corpus para a PC.

Os resumos foram analisados e reescritos em Escrita Simples (SOUSA, 2011; 2017), o que gerou anotações e observações, que resultaram em diretrizes iniciais para a Escrita Simples em DC, no formato de resumo. Os resultados encontrados podem guiar novas diretrizes para a elaboração da comunicação de divulgações científicas, colaborando para uma produção de conhecimento científico mais acessível e compreensível ao público não especializado, estreitamento da comunicação entre ciência e sociedade.

0 trabalho está estruturado da seguinte forma: a seção 2 apresenta o referencial teórico no que tange à Divulgação Científica; a seção 3 expõe uma conceituação da Escrita Simples. Na seção 4, é 
explicitada a metodologia do estudo, sendo os resultados e discussão abordados na seção 5. As considerações finais são apresentadas na sexta e última seção.

\title{
2 DIVULGAÇ̃̃O CIENTÍFICA E SOCIEDADE
}

O ciclo de uma pesquisa científica é concluído quando, em última instância, atende ao objetivo de comunicar, ou seja, os resultados são materializados na forma de publicações científicas acadêmicas, à comunidade científica e à sociedade. Assim, os resultados de pesquisas científicas têm por objetivo a DC. De acordo com Albagli (1996), a DC é caracterizada como um processo de comunicação que inclui a aplicação de recursos técnicos para a adaptação da informação tecnocientífica ao público em geral. Neste entendimento, o termo divulgação tem por fundamento traduzir os resultados científicos de uma linguagem especializada a uma escrita comum.

Há de se considerar a crescente inserção socioeconômica da ciência, que supõe a aceitação, pela sociedade, da atividade científica e de suas aplicações (ALBAGLI, 1996), o que confere caráter primordial à DC, com vistas a garantir a manutenção da equidade na difusão científica, em uma perspectiva que potencialize a descentralização das informações sobre produção de conhecimento, para além da comunicação entre pares.

A função da DC, conforme Albagli (1996), pode ser: (a) educacional - buscando a ampliação do conhecimento e da compreensão do público leigo a respeito do processo científico e sua lógica; (b) cívico - com vistas ao desenvolvimento de uma opinião pública informada sobre os impactos do desenvolvimento científico e tecnológico sobre a sociedade; (c) mobilização popular - com o objetivo de ampliação da possibilidade e da qualidade de participação da sociedade na formulação de políticas públicas, a partir do debate, interlocução e apropriação das informações recebidas.

Se está inferindo que a adoção de Escrita Simples, tendo em vista que a DC visa a contemplar as funções mencionadas nos itens (a; b; c) (SOUSA, 2011; 2017), quando aplicada aos textos de DC, como estratégia de acessibilidade para todos (SOUSA, 2011; 2017), pode promover a compreensão e a participação deste público, seja em caráter educacional, cívico ou de mobilização popular.

A Escrita Simples pode promover a compreensão de conteúdos científicos sobre temas gerais e promover a apropriação de conteúdo, permitindo ao sujeito leitor a construção de novos conhecimentos por meio da interação com o conteúdo comunicacional da DC. Concorda-se com Albagli (1996) quando refere que, a partir da DC, a sociedade pode ampliar seu interesse e preocupação em melhor conhecer e monitorar o que se faz na ciência e o que dela resulta. Na próxima seção, apresenta-se o conceito e parâmetros para a Escrita Simples.

\section{ESCRITA SIMPLES COMO ESTRATÉGIA DE ACESSIBILIDADE}

\author{
A Associação Brasileira de Normas Técnicas (ABNT, 2016, p. 1), define como acessibilidade:
}


Possibilidade e condição de alcance para utilização, com segurança e autonomia, de espaços, mobiliários, equipamentos urbanos, edificações, transportes, informação e comunicação, inclusive seus sistemas e tecnologias, bem como de outros serviços e instalações abertos ao público, de uso público ou privados de uso coletivo, tanto na zona urbana como na rural, por pessoa com deficiência ou com mobilidade reduzida.

Já a Convenção sobre os Direitos das Pessoas com Deficiência adotada pela Organização das Nações Unidas (ONU, 2009) e ratificada pelo Brasil com caráter de emenda constitucional, no artigo $9^{\circ}$, afirma que:

[...] a fim de possibilitar às pessoas com deficiência viver com autonomia [...], os Estados Partes devem tomar medidas para assegurar-lhes o acesso, em igualdade de oportunidades com as demais pessoas, ao meio físico, ao transporte, à informação e à comunicação [...], (BRASIL, 2009, p.).

Vê-se, portanto, a importância de informações claras e simples de DC para a apropriação do conhecimento, sendo essencial que as pessoas com deficiência recebam informações claras e fáceis de ler e compreender. Nesse sentido, considerando a necessidade de acesso equânime de diversos públicos aos meios de divulgação e comunicação científica, é necessária a adoção de estratégias e recursos para promover condições de acessibilidade para todos.

Uma das estratégias que busca tornar a forma da escrita acessível a todos é a Escrita Simples ou a Linguagem Simples - Plain Language (PLAINLANGUAGE.GOV, 2011), que, assim como o método EKARV preconiza, consiste na reescrita do texto, mantendo tanto quanto possível o original, mas simplificando o vocabulário e a sintaxe. 0 método de Escrita Simples foi criado por Margareta Ekarv na Suécia, nos anos de 1960 (EKARV, 1994; 1999). Para Martins (2014), o método consiste em utilizar palavras simples, entendidas pela maioria dos usuários, partindo de conceitos familiares, respeitando o conhecimento que a maioria das pessoas têm sobre os assuntos tratados.

Para Mineiro (2006, p. 8), trata-se de "uma linguagem direta e clara dirigindo-se pessoalmente ao leitor". Martins (2014) cita uma série de atributos que os textos em Escrita Simples devem contemplar, como: serem curtos, relevantes, acessíveis e envolventes; e condensar as informações, suprimindo o supérfluo, mantendo o essencial e estimulando os leitores. Importante salientar que se deve simplificar a informação sem retirar o valor ou a seriedade das informações do texto, haja vista ser possível, por meio da Escrita Simples, fomentar a igualdade de oportunidades de forma que todos tenham acesso às mesmas informações (INCLUSION EUROPE, 2019).

O Accessible Portugal (2018) considera que a Escrita Simples é uma técnica que associa princípios de redação e de design para tornar o texto claro e compreensível ao leitor. Considera-se que todos se beneficiam com a Escrita Simples, desde pessoas com deficiência intelectual ou com déficit de atenção, crianças em fase de aprendizagem, disléxicos ou pessoas com pouca escolaridade, ou mesmo estrangeiros (e emigrantes) que não dominam a língua ou os surdos, muitas vezes com a Língua de Sinais como primeira língua.

Sousa (2017) aponta para uma série de parâmetros a serem seguidos para se escrever segundo o método de Escrita Simples, apresentados no Quadro 1. 
Quadro 1 - Regras e parâmetros para se escrever com Escrita Simples.

\begin{tabular}{|c|c|c|}
\hline Linguagem & Estrutura & Formatação \\
\hline $\begin{array}{l}\text { - Fazer um resumo da história dando } \\
\text { prioridade à linha narrativa; } \\
\text { - Simplificar a linguagem no vocabulário } \\
\text { e sintaxe mantendo o máximo do original; } \\
\text { - Quando necessário, substituir alguns } \\
\text { termos, ou expressões, suprimir algumas } \\
\text { partes do texto ou acrescentar outras; } \\
\text { - Usar estrutura simples, com a ordem } \\
\text { natural das palavras; } \\
\text { - Evitar frases subordinadas, adjetivos } \\
\text { rebuscados e advérbios; } \\
\text { - Dar preferência à voz ativa. }\end{array}$ & $\begin{array}{l}\text { - Utilizar frases curtas; } \\
\text { - Colocar vírgulas nas pausas } \\
\text { naturais da frase; } \\
\text { - Dividir o texto por linhas, com } \\
\text { no máximo } 45 \text { caracteres por } \\
\text { linha; } \\
\text { - Fazer coincidir o fim natural } \\
\text { da frase com o fim da linha; } \\
\text { - Utilizar parágrafos de no } \\
\text { máximo } 10 \text { linhas. }\end{array}$ & $\begin{array}{l}\text { - Alinhar o texto à esquer- } \\
\text { da; } \\
\text { - Utilizar espaços entre } \\
\text { parágrafos; } \\
\text { - Utilizar espaço entre } \\
\text { linhas de 1,5; } \\
\text { - Utilizar letras sem serifa; } \\
\text { - Utilizar letras com corpo } \\
\text { não inferior a 12pt. }\end{array}$ \\
\hline
\end{tabular}

Fonte: Adaptado de Sousa (2017).

Sobre o parâmetro de linguagem, Martins (2014) salienta que se deve recorrer à voz ativa por esta ser mais direta e afirmativa, evitando estrangeirismos, metáforas e palavras longas quando existirem equivalentes mais breves e objetivos. Martins (2014) indica a importância em manter as mesmas palavras para os mesmos conceitos, embora afete o estilo do texto, pois reforça o vocabulário utilizado. Ainda quanto à estrutura, cada frase deve corresponder a uma afirmação (com no máximo 15 a 20 palavras) e cada parágrafo deve relacionar-se a um assunto.

Mesmo curtos, frases e parágrafos podem ter tamanho variado, conforme o ritmo esperado para a leitura. Deve-se evitar dividir sílabas e usar muitos outros elementos como parênteses, hifens, abreviaturas e siglas. Segundo Mineiro (2006), deve-se evitar a linguagem com termos técnicos, mas a introdução de novo vocabulário num texto pode ter caráter pedagógico, se forem usados exemplos, explicações ou comparações para compreensão da terminologia.

Quanto à formatação ou design, as fontes devem ter tamanho apropriado à leitura e o texto deve estar, preferencialmente, alinhado à esquerda para evitar espaços vazios no meio das frases, o que pode dificultar a leitura. 0 espaçamento maior entre linhas favorece as pessoas com incapacidades cognitivas e baixa visão, que têm dificuldades em acompanhar um texto com linhas muito próximas umas das outras. A Comissão Europeia (2019) apresenta 10 sugestões para redação clara de documentos oficiais para a população, tal como: organize o seu documento; seja breve e claro; organize as frases; vá direto ao assunto, evite as abstrações; prefira a voz ativa; entre outros.

A Comissão Europeia (2019, p. 2) justifica a redação clara por três motivos: (a) trabalhar em conjunto de forma mais eficaz; (b) evitar mal-entendidos; e (c) dispor favoravelmente o leitor. Conforme se apresenta nos procedimentos metodológicos, foram realizadas adaptações de textos científicos a partir dos parâmetros descritos, os quais foram empregados na reescrita de resumos, permitindo a sistematização de diretrizes para tal aplicação em âmbito acadêmico. 


\section{METODOLOGIA}

Esta pesquisa, de caráter descritivo (SAMPIERI; COLLADO; LUCIO, 2013), tem como objetivo verificar a viabilidade da adaptação de resumos científicos para Escrita Simples, como uma estratégia de promoção do acesso à DC, tendo em vista a carência de iniciativas nesta perspectiva. Nesse sentido, realizou-se o levantamento teórico a partir de documentos de referência disponíveis, nesse caso, internacionalmente (PLAINLANGUAGE.GOV, 2011; INCLUSION EUROPE, 2019; COMISSÃO EUROPEIA, 2019) e de artigos científicos, com vistas a identificar estudos dedicados à: 1) análise da forma de escrita do modelo de produção científica atual; 2) o papel da Divulgação Científica frente à sociedade; 3) recursos de acessibilidade usados para a comunicação, com o foco na Escrita Simples.

A partir disto, foi formulado o objetivo de aplicação de uma Prova de Conceito e, em seguida, a execução da adaptação dos resumos selecionados para Escrita Simples. A Prova de Conceito serve de modelo prático para a verificação da adaptação de resumos científicos para Escrita Simples. Foram selecionados como corpus 5 (cinco) resumos científicos oriundos de 3 teses de doutorado acadêmico e 2 dissertações de mestrado acadêmico, junto ao Programa de Pós-Graduação em Design da Universidade Federal do Rio Grande do Sul (UFRGS), durante o ano de 2019 e disponibilizadas publicamente no repositório digital da UFRGS, a plataforma Lume (LUME UFRGS, 2019). A amostra de trabalho ocorreu pela facilidade de acesso às tais produções científicas.

A adaptação dos resumos para a Escrita Simples teve objetivo exploratório, de reflexão e proposição de diretrizes iniciais para a aplicação da técnica a resumos e comunicações em DC. As adaptações seguiram os parâmetros do método EKARV (EKARV, 1944; 1999) e os passos da Escrita Simples propostos por Sousa (2017). Ressalta-se que as proposições da Escrita Simples se baseiam, inicialmente, em textos literários e/ou governamentais (COMISSÃO EUROPEIA, 2019; PLAINLANGUAGE.GOV, 2011), neste estudo, tendo sido incorporados à aplicação em textos de caráter científico. A seguir, é apresentada a discussão acerca da adaptação dos resumos científicos para a Escrita Simples.

\section{ANÁLISE E DISCUSSÃO DOS DADOS}

Em abordagem quantitativa, na Tabela 1 são apresentados os dados de números de palavras e de caracteres dos 5 resumos analisados, em uma associação entre os resumos científicos originais e os resumos reescritos em Escrita Simples. 
Tabela 1 - Relação de palavras e caracteres dos resumos originais e após adaptação para Escrita Simples

\begin{tabular}{|c|c|c|c|}
\hline & & Palavras & Caracteres \\
\hline Resumo 1 & Original & 273 & 1899 \\
\hline \multirow[t]{2}{*}{ https://www.lume.ufrgs.br/handle/10183/199540 } & Reescrita & 255 & 1604 \\
\hline & Diferença & $-18(6,59 \%)$ & $-295(15,53 \%)$ \\
\hline Resumo 2 & Original & 312 & 2153 \\
\hline \multirow[t]{2}{*}{ https://www.lume.ufrgs.br/handle/10183/199539 } & Reescrita & 318 & 2019 \\
\hline & Diferença & $+6(-1,92 \%)$ & $-134(6,22 \%)$ \\
\hline Resumo 3 & Original & 239 & 1589 \\
\hline \multirow[t]{2}{*}{ https://www.lume.ufrgs.br/handle/10183/199569 } & Reescrita & 214 & 1347 \\
\hline & Diferença & $-25(10,46 \%)$ & $-242(15,23 \%)$ \\
\hline Resumo 4 & Original & 232 & 1542 \\
\hline \multirow[t]{2}{*}{ https://www.lume.ufrgs.br/handle/10183/199299 } & Reescrita & 216 & 1329 \\
\hline & Diferença & $-16(6,90 \%)$ & $-213(13,81 \%)$ \\
\hline Resumo 5 & Original & 356 & 2533 \\
\hline \multirow[t]{4}{*}{ https://www.lume.ufrgs.br/handle/10183/199584 } & Rescrita & 289 & 1877 \\
\hline & Diferença & $-67(18,82 \%)$ & $-656(25,90 \%)$ \\
\hline & & $\begin{array}{l}\text { Média de redução } \\
\text { de palavras: }\end{array}$ & $\begin{array}{c}\text { Média de redução } \\
\text { de caracteres: }\end{array}$ \\
\hline & & $-24(8,2 \%)$ & $-308(15,3 \%)$ \\
\hline
\end{tabular}

Fonte: Elaborada pelos autores.

Pelos números apresentados na Tabela 1, percebe-se que, embora não tenha havido redução significativa de palavras (menos 24 palavras em média), a redução de caracteres se apresentou de forma significativa (308 caracteres a menos em média). Não ocorreu em todos os resumos a diminuição de palavras, pois isso depende do estilo de redação de cada resumo. No caso do Resumo 2, inclusive, houve a necessidade de acréscimos para especificar melhor questões do texto.

Há de se considerar que para este estudo, o objetivo adotado na Escrita Simples foi o de simplificar o texto, apresentando a informação de maneira mais clara, e não o de supressão do texto. Mesmo que esta estratégia possa desencadear a diminuição de palavras e caracteres, essa não é a principal finalidade. Essa diminuição não implica na diminuição do bloco de texto. Em função da formatação sugerida pelas diretrizes da Escrita Simples, o bloco de texto poderá vir a ocupar mais espaço do que o texto original. 
Essa formatação da Escrita Simples que visa a facilitar a leitura pode ser observada no Quadro 2, considerando maiores áreas de arejamento com um espaço entre linhas maior e a configuração em blocos de texto bem definidos, além do uso de fontes com leitura mais fácil em função do seu desenho, tamanho e alinhamento. Tendo isso em vista, a adaptação de um parágrafo de um dos resumos é apresentada no Quadro 2.

\section{Quadro 2 - Processo de adaptação para Escrita Simples}

\begin{tabular}{|c|c|c|}
\hline Texto original & $\begin{array}{c}\text { Em tempos de hegemonia digital na vida contemporânea, a questão da escrita adquire } \\
\text { grande importância, tanto sob o aspecto da produção de conteúdo (o que se escreve), } \\
\text { quanto sob o aspecto operacional (como se escreve). Especificamente em relação às } \\
\text { questões operacionais, observa-se que a letra manual pode estar ficando obsoleta. } \\
\text { Diante do impacto das novas mídias, antigos modelos caligráficos, que apoiam a aquisi- } \\
\text { ção da escrita manual na escola, precisam ser revistos e estudados, buscando facilitara } \\
\text { conquista de uma letra pessoal legível, rápida, simples e adequada aos novos tempos. }\end{array}$ \\
\hline Primeiro passo & \multicolumn{1}{c}{$\begin{array}{c}\text { Substituir alguns termos ou expressões por outros; } \\
\text { Suprimir algumas partes do texto; }\end{array}$} \\
\hline Acrescentar outras, quando necessário.
\end{tabular}




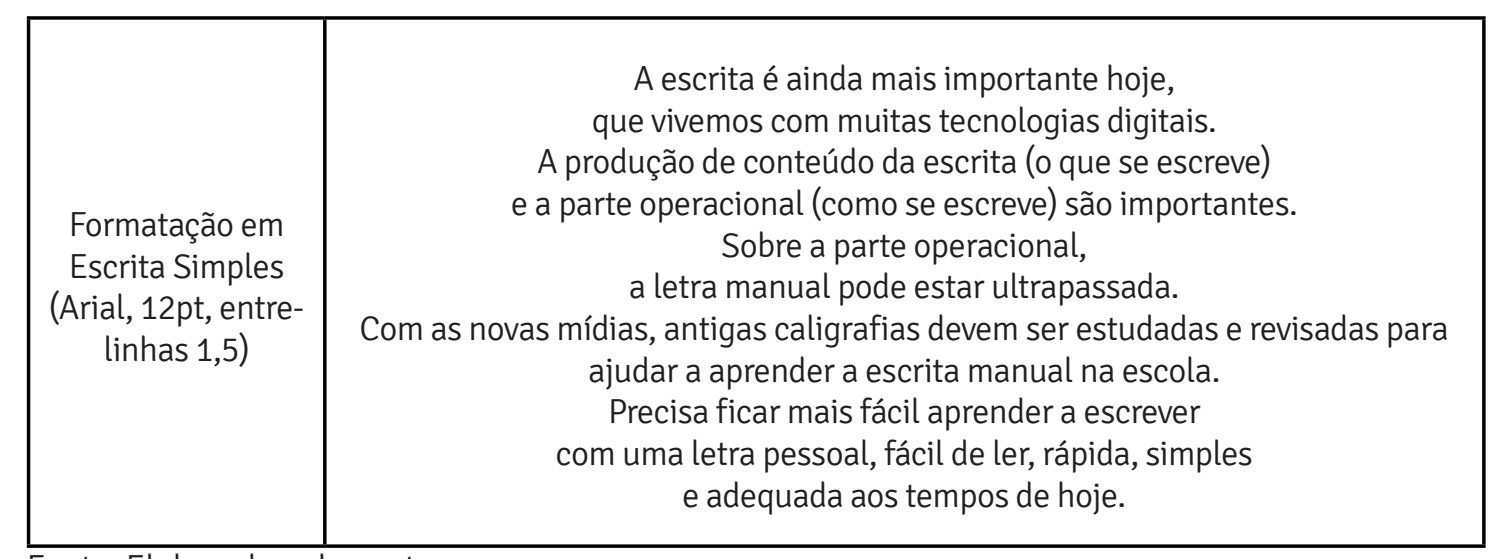

Fonte: Elaborado pelos autores.

Em alguns casos, foram utilizadas palavras simples e coloquiais em substituição a termos menos conhecidos. Além disso, houve dificuldade em quebrar as frases longas em frases mais curtas, em virtude do extenso encadeamento de ideias. No estudo, buscou-se ainda manter o gênero Resumo Científico, primando pela sua adaptação para Escrita Simples e não uma recontagem da história relatada no resumo. Outra questão que implica na relação da Escrita Simples com o design e princípios de diagramação e layout do resumo é a mudança significativa de formato que ocorre com o texto quando é reescrito.

Os blocos de textos, considerando as restrições de tamanhos de frases e a orientação de buscar quebrar cada linha de acordo com a finalização da frase, tornam-se mais extensos em termos de espaço vertical ocupado, com muitas linhas. Para tanto, buscou-se referências nos documentos apresentados (PLAINLANGUAGE.GOV, 2011; INCLUSION EUROPE, 2019; COMISSÃO EUROPEIA, 2019), para se fazer uma divisão das informações em blocos, mesmo que com frases um pouco mais longas, mas que facilitassem a leitura.

Durante o processo de aplicação da Escrita Simples aos resumos analisados, houve a necessidade de avaliação do número de caracteres por linha e da conclusão de uma ideia central por linha, ainda coincidente com a pausa natural de leitura, optando-se por estender um pouco o número de caracteres por linha em prol do bom entendimento ou conclusão da ideia que se quer passar naquela linha. Esse aspecto visual dos textos pode ensejar mudanças não só na apresentação enquanto formatação de texto científico como também na interface de plataformas digitais de repositórios digitais onde os trabalhos são disponibilizados. A partir da aplicação da Escrita Simples nos resumos e consequente análise dos resultados, foram acrescidas às diretrizes para Escrita Simples algumas orientações específicas (QUADRO 3). 
Quadro 3 - Diretrizes para escrita de resumos científicos com Escrita Simples

\begin{tabular}{|c|c|c|}
\hline Linguagem & Estrutura & Formatação \\
\hline $\begin{array}{l}\text { - Manter conceitos cruciais da pesquisa, } \\
\text { sem desvalorizá-los ou mudar seu nome; } \\
\text { - Dividirfrases com mais de } 3 \text { sentenças; } \\
\text { - Referir-se ao autor ou autora (no } \\
\text { caso de dissertação/tese) ou autores } \\
\text { (artigos) na voz ativa; } \\
\text { - Evitar a escrita no modo impessoal } \\
\text { "conduziu-se" ou “foi conduzida"; } \\
\text { - Explicitar o significado de siglas; } \\
\text { - Explicitar que se está citando um au- } \\
\text { tor, no caso de resumos com citação; } \\
\text { - Simplificar também os títulos; geral- } \\
\text { mente, podem ser longos e complexos. }\end{array}$ & $\begin{array}{l}\text { - Quando necessário, acrescen- } \\
\text { tar palavras para tornar uma fra- } \\
\text { se mais clara ou até redundante } \\
\text { (para retomar ou reforçar uma } \\
\text { ideia/conceito); } \\
\text { - Verificar quando quebras de li- } \\
\text { nha envolvem listagens; buscar } \\
\text { manter um item em cada linha; } \\
\text { - Em situações específicas, como } \\
\text { metodologia, apresentar informa- } \\
\text { ções em lista ou repetindo ele- } \\
\text { mentos (redundância), com vistas } \\
\text { a facilitar a compreensão do enca- } \\
\text { deamento entre os procedimentos. }\end{array}$ & $\begin{array}{l}\text { - Criar divisão de parágrafos de } \\
\text { acordo com os blocos de infor- } \\
\text { mação do resumo original; } \\
\text { - Dividir também o título de } \\
\text { acordo com as quebras de linha } \\
\text { e } 45 \text { caracteres por linha, ou o } \\
\text { mais próximo disso, com vistas } \\
\text { a concluir uma ideia central } \\
\text { por frase. }\end{array}$ \\
\hline
\end{tabular}

Fonte: Elaborado pelos autores.

Cabe destacar que, no contexto deste estudo, as diretrizes propostas têm caráter de Prova de Conceito, sendo elementos iniciais ao seguimento desta investigação. Portanto, compreende-se que são complementares às apresentadas na fundamentação teórica, não objetivando sobrepor-se a elas. Bem como é necessário diversificar as áreas de conhecimento dos resumos e fazer testes com diversos públicos para uma verificação da eficiência dessa estratégia. Mesmo assim, acredita-se que as diretrizes propostas podem contribuir para acessibilidade de resumos científicos, mesmo que ainda necessitem de melhorias e aprofundamento.

\section{CONSIDERACÕ̃ES FINAIS}

Este estudo verificou a viabilidade da adaptação de resumos científicos para Escrita Simples, como uma iniciativa com vistas a promover a acessibilidade em Divulgação Científica. Espera-se que as 12 diretrizes apontadas, somadas aos parâmetros que formaram a base deste trabalho, possam ser uma primeira iniciativa na direção de tornar a ciência mais acessível, mesmo que se possa caminhar junto a outras adaptações, como da interface de bases de dados de disponibilização de trabalhos científicos. Esse contexto pode beneficiar a todos, incluindo o público com necessidades específicas, que poderá se deparar com um trabalho científico e possivelmente entendê-lo melhor.

A Escrita Simples é uma das estratégias de acessibilidade complementar a outras que precisam ser previstas no processo de efetiva inclusão da DC. Além disso, a Escrita Simples pode ser um recurso de acessibilidade para a comunicação em diversas áreas, como em documentos públicos, em editais, 
sentenças e documentos jurídicos, também em âmbitos mais dinâmicos, como o ensino a distância. A premissa é de que os formatos alternativos possam permitir que cada indivíduo se aproprie e atribua sentido aos materiais e informações da maneira que melhor the convir. Para tanto, deve-se sempre considerar os três princípios básicos citados: o que se quer transmitir (conteúdo); a forma como se quer apresentar o conteúdo (estilo, linguagem e construção); a imagem que se pretende (design). Assim como buscar compreender as especificidades de cada aplicação e contexto.

Espera-se, em breve, aprofundar os estudos, por meio da análise de um número maior de resumos científicos, com vistas à validação das diretrizes propostas com públicos específicos, de modo a incluir a análise do emprego da Escrita Simples em outros contextos. Desse modo, se possibilita que a informação seja lida e compreendida por qualquer pessoa, independentemente das suas capacidades linguísticas ou cognitivas, ao simplificar o seu conteúdo sem desvalorizá-lo, melhorar a sua linguagem e otimizar o seu formato.

\section{REFERÊNCIAS}

ABNT - Associação Brasileira de Normas Técnicas. NBR 16452 - Acessibilidade na comunicação Audiodescrição. Rio de Janeiro: ABNT, 2016.

ACCESSIBLE PORTUGAL. Escrita simples para uma leitura fácil. 23 mar. 2018. Disponível em: https://url.gratis/N0Ne9. Acesso em: 5 out. 2019.

ALBAGLI, S. Divulgação científica: informação científica para a cidadania? Ci. Inf., Brasília, v. 25, n. 3, p. 396-404, set./dez. 1996.

BRASIL. Presidência da República. Casa Civil. Subchefia para Assuntos Jurídicos. Decreto nº 6.949, de 25 de agosto de 2009. Promulga a convenção sobre os direitos das pessoas com deficiência. Brasília, 2009.

CARDOSO, E.; MARTINS, D. S.; KAPLAN, L. Diretrizes para o desenvolvimento de livros infantis multiformato acessíveis. : P\&D, Congresso Brasileiro de Pesquisa e Desenvolvimento em Design, 13, 5 a 8 nov. 2018. Anais [...], Univille, Joinville (SC), 2018.

COMISSÃO EUROPEIA. Redigir com clareza. Luxemburgo, Serviço das Publicações da União Europeia, União Europeia, 2015. Disponível em: https://url.gratis/DlbJ2. Acesso em: nov. 2019.

EKARV, M. Combating redundancy: writing texts for exhibitions. In: GREENHILL, Eilean Hooper (ed.). The educational role of the museum. London: Routledge, 1994/1999. p. 201-204.

FEIJÓO, J.; CHAMIZO, S.; TRAPERO, J. El diseño narrativo: un nuevo paradigma para la comunicación. 2019. Disponível em: https://url.gratis/h8wOd: Acesso em: out. 2019. 
INCLUSION EUROPE. Programa de aprendizagem ao longo da vida, 2019. Disponível em: https:// url.gratis/laGjt. Acesso em: nov. 2019.

MARTINS, H. M. L. E. P. 0 museu nacional de arte antiga, o edifício e a sua história: contributos para um projeto de comunicação. 2014. 153 f. Dissertação (Mestrado) - Faculdade de Ciências Sociais e Humanas, Universidade Nova de Lisboa, Lisboa, 2014.

MERCADANTE, M. T.; GAAG, R. J.; SCHWARTZMAN, J. S. Transtornos invasivos do desenvolvimento não-autísticos: síndrome de Rett, transtorno desintegrativo da infância e transtornos invasivos do desenvolvimento sem outra especificação. Revista Brasileira de Psiquiatria, v. 28, suppl.1, São Paulo, maio, 2006.

MINEIRO, C. Mas as peças não falam por si? A importância do texto nas exposições. 2007. Disponível em: https://url.gratis/ypc30. Acesso em: 27 jan. 2019.

PLAINLANGUAGE.GOV. Federal Plain Language Guidelines: improving communication from the Federal Government to the public. Mar. 2011. Disponivel em: https://url.gratis/Cgadt. Acesso em: nov. 2019.

SAMPIERI, R.; COLLADO, C.; LUCIO, M. Metodologia de pesquisa. Porto Alegre: Penso, 2013.

SOUSA, C. A comunicação aumentativa e as tecnologias de apoio. Cadernos Sacausef VI: A acessibilidade dos recursos educativos digitais, Porto, n. 6, p. 51-63, nov. 2011.

SOUSA, C. Literatura para todos. Curso cultura e acessibilidade: pesquisa, formação e produção. Porto Alegre, 2017. 
1 Mestre em Design - UniRitter; Doutorando em Design no Programa de Pós-Graduação em Design da Universidade Federal do Rio Grande do Sul - UFRGS; Designer na CWI Software. E-mail: rafaelpeduzzi@gmail.com

2 Doutor em Design pelo Programa de Pós-Graduação em Design - PGDesign - UFRGS; Professor do Departamento de Design e Expressão Gráfica e Professor Colaborador no PGDesign da Universidade Federal do Rio Grande do Sul UFRGS). E-mail: eduardo.cardoso@ufrgs.br

3 Doutor em Informática na Educação pela Universidade Federal do Rio Grande do Sul - UFRGS; Pós-Doutorando em Educação pela Universidade de Caxias do Sul (UCS) no Programa de Pós-Graduação em Educação.

E-mail: correaygorprof@gmail.com

4 Doutora em Informática na Educação pela Universidade Federal do Rio Grande do Sul - UFRGS; Professora do Departamento de Educação e Humanidades da Universidade Federal de Ciências da Saúde de Porto Alegre.

E-mail:spohrfulvia@gmail.com

5 Doutor em Computação pela Universidade Federal do Rio Grande do Sul - UFRGS; Professor Adjunto no Departamento Interdisciplinar - Campus Litoral Norte e PGDesign - UFRGS. E-mail: vinicius.gadis@ufrgs.br

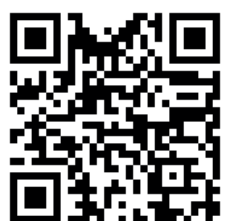

A autenticidade desse artigo pode ser conferida no site https://periodicos. set.edu.br

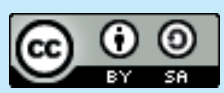

Este artigo é licenciado na modalidade acesso abertosob a Atribuição-Compartilhalgual CC BY-SA
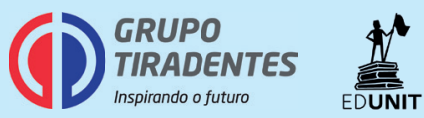